\title{
Behavioural Restriction
}

\author{
Georgia J. Mason and Charlotte C. Burn
}

\begin{abstract}
Captivity often restricts the abilities of animals to perform natural behaviour. Here, we review how this constraint affects psychological welfare by preventing the meeting of motivations. One means by which this happens is through frustrating specific motivations pertaining to particular behavioural systems. This can occur when constrained behaviours are 'behavioural needs': activities that animals have instincts to perform even in environments where they are not biologically necessary for fitness (e.g. non-nutritive sucking by calves). It can also occur when deficits or external cues in the environment elicit strong motivations to behave a certain way (e.g. the lack of burrow-like structures triggering digging attempts in gerbils). Furthermore, given that humans suffer boredom in monotonous conditions that resemble those of the environments of many captive animals, and that many animals actively seek stimulation, it seems likely that, at least for some individuals in some species, behavioural restriction also harms welfare by thwarting general motivations to seek variety and/or to avoid monotony, thus causing boredom.
\end{abstract}

\subsection{Introduction}

If captive animals are well fed and physically healthy, is that enough to ensure good welfare? This has long been doubted: as long ago as 1863, Blake wrote the famous line 'A robin redbreast in a cage puts all heaven in a rage'. Captive conditions are often too 'impoverished' (i.e. barren - without appropriate stimuli or substrates), or too small, to allow animals to perform behaviour patterns that they would display in more natural settings, a constraint known as behavioural restriction. This holds for billions of animals worldwide: intensively farmed poultry, pigs, cattle, sheep, mink and foxes; laboratory rats, mice, primates and others; stabled horses and many zoo animals; fish in tanks and aquaria; caged pet parrots, canaries and other birds; and cats, dogs and wild animals kept in breeding facilities (Fig. 7.1). Behavioural restriction often elicits concern, perhaps because it is so negative for humans to experience; indeed, from sending a naughty child to its room to locking a prisoner into solitary confinement, behavioural restriction plays a major part in human punishment. The issue of whether behavioural restriction truly matters to captive animals was first taken up by biologists following the Brambell Committee's 1965 Report to the UK government (Brambell Committee, 1965) - a report focusing on intensive farming, but addressing issues relevant far beyond farms. This report concluded that:

The degree to which the behavioural urges of the animals are frustrated under the particular conditions of the confinement, must be a major consideration in determining its acceptability or otherwise.

William Thorpe's influential ethological appendix to the Brambell Report argued that animals cannot simply abandon natural behaviours when captivity prevents them or makes them redundant:

A very large part of animal behaviour is basically determined by instinctive or innate abilities, proclivities and dispositions.

The UK's Farm Animal Welfare Council (FAWC) followed this in 1979 by including 'the freedom to express normal behaviour by providing sufficient space, proper facilities, and the company of the animal's own kind' in its 'Five Freedoms' prerequisites for good welfare (FAWC, 2009).

This chapter covers what biologists have since discovered about the psychological effects of behavioural restriction, and how it can impair welfare even when physical health is fine. Several psychological aspects of impoverished environments are relevant here, including those that sensory environments may be inappropriate (e.g. over- or under-stimulating), and that captive animals' lack of control over their 
lives may be inherently stressful. Our emphasis, however, is on the motivational effects of such environments - on consequences such as specific frustrations and more generalized boredom. First, we briefly review the techniques used to identify behaviour patterns that animals need to perform if welfare is not to be compromised (Section 7.2). Next, we give examples, focusing on the best understood and emphasizing the specific natural behaviour patterns that concerned Thorpe and Brambell (Section 7.3). We end by discussing whether impoverished environments also cause boredom (Section 7.4).

(a)
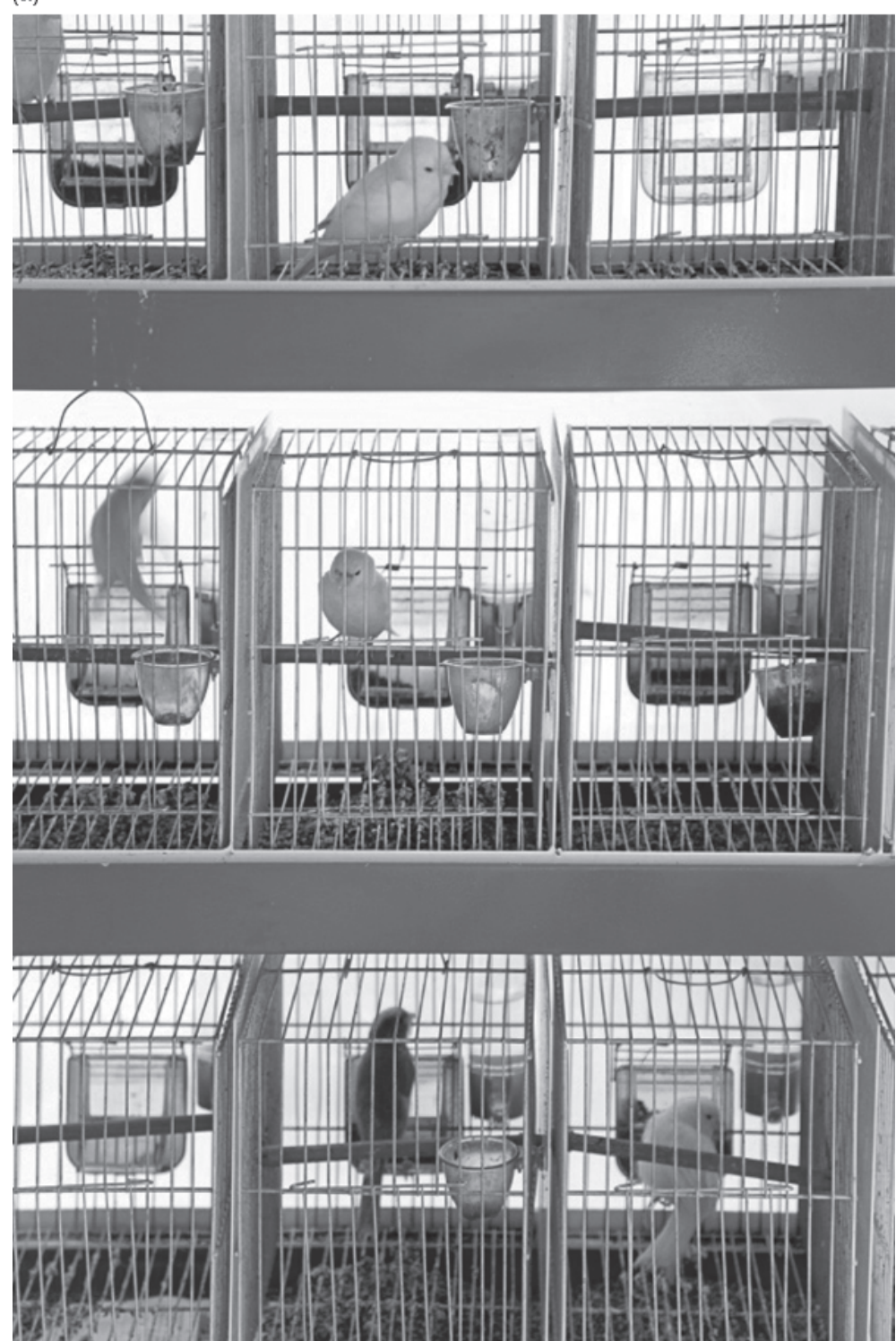

Fig. 7.1. Animals in behaviourally restrictive conditions. The sight of animals housed in small, barren enclosures often raises welfare questions. For example, Fig 7.1a shows canaries in a Greek pet shop (Photo: iStock Photo): do they miss social contact or being able to fly? Fig. 7.1b shows intensively farmed pigs (Photo: iStock Photo): does it matter that they were taken from their mothers while still suckling? Do they miss natural behaviours like being able to root?

Continued 


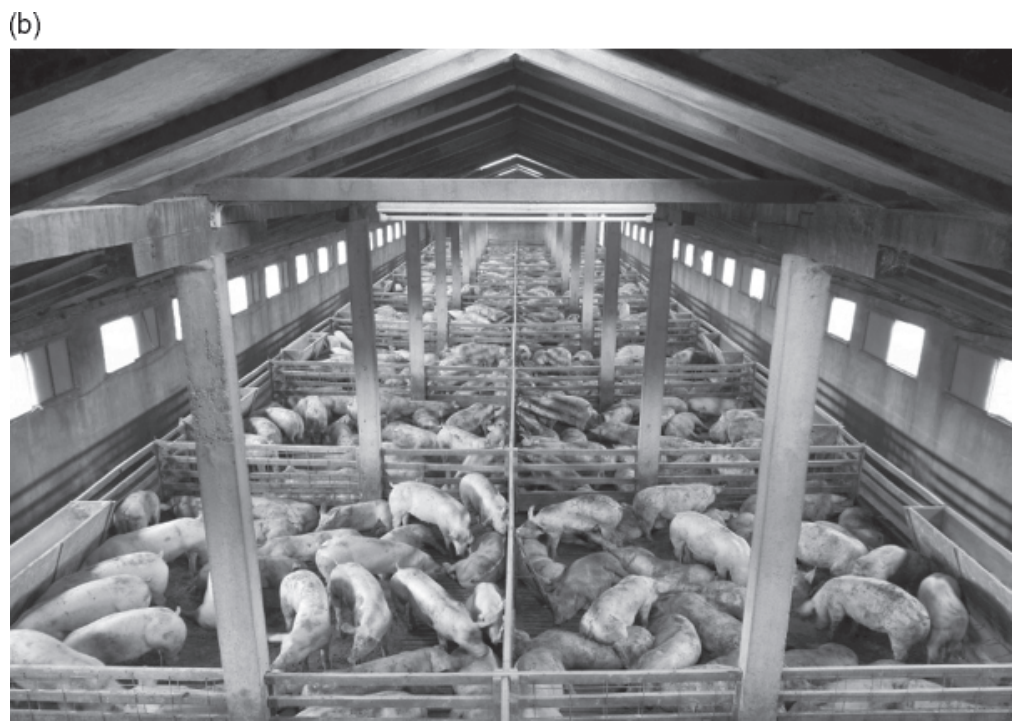

Fig. 7.1. Continued.

\subsection{Identifying Natural Behaviour Patterns That Are Important for Welfare, and Understanding Why}

\subsubsection{Which natural behaviour patterns, in principle, are important for welfare?}

Encouraging captive animals to perform all the behaviour patterns evident in the wild is neither sensible nor humane. Animals in nature often have lives that could be described as 'poor, nasty, brutish and short' (Hobbes, 1651). In such conditions, many behaviours are just responses to adversity: animals compete aggressively for resources such as food and mates; they eat non-preferred food items because preferred diets are unavailable; they defend large home ranges when resource availability is low; they migrate huge distances to find water; they eat their own offspring; they hide or flee from predators, screaming if caught; and so on. All these behaviours are perfectly natural, but their absence in captivity should not raise welfare concerns because they are elicited by external stimuli or changes in physiological state that should be absent in animals whose safety, health and nutritional needs are ensured.

Welfare researchers, therefore, do not catalogue all natural behaviours to try and ensure that each is performed in captivity. Instead, they try to identify the subset whose performance is likely to benefit welfare, because driven by high motivations that still occur in captivity: 'behavioural deprivation implies not only that an animal is prevented from performing behaviour ... but that adverse effects arise as a result' (Dawkins, 1988). These key behaviours comprise responses known or assumed to be elicited by external stimuli present, desirably or undesirably, in captivity (e.g. cues from food, potential mates, infants or potential predators); and responses elicited by internal physiological mechanisms that - again - are unavoidable or even desirable in captivity (e.g. hormonal changes preceding parturition/egg laying). Critical here is the idea that frustrating motivated behaviours compromises welfare. Next, we therefore discuss links between motivation and emotion; how frustration is identified; and how so-called 'behavioural needs' both differ from and resemble other strong motivations.

\subsubsection{Frustrated motivation as an animal welfare issue}

Motivational states are states within the brain that determine the likelihood and intensity of a given behavioural pattern, and the efforts that animals will make in order to perform it. Motivated behaviours have four key characteristics (Hughes and Duncan, 1988; Jensen and Toates, 1993; Mason and Bateson, 2009). First, the degree to which they are motivated (i.e. the magnitude of the underlying motivational state) is typically determined by a 
combination of physiological state (e.g. blood sugar levels) and external stimuli (e.g. food odours). Secondly, motivated behaviours broadly have two phases: an 'appetitive' phase, in which the animals flexibly search or prepare for the opportunity to perform a 'consummatory' phase (e.g. courtship paves the way for mating). This consummatory behaviour is often more stereotyped and species typical, involves engagement with external stimuli in a way that reduces the underlying motivation (e.g. eating reduces motivations to forage), and typically seems elicited by these very stimuli, once successful appetitive behaviour has brought them into proximity. Thirdly, the actual performance of these activities, independent of physiological outcomes or effects on the animal's world, can sometimes help reduce the underlying motivation; thus, very the act of ingesting food, for example, plays a role in satiety. The fourth key characteristic of motivated behaviours is that emotions appear to be important in their control. In particular, satisfying strong motivations seems emotionally positive, while being unable to satisfy strong motivations - a situation known as 'frustration' - seems very negative. Evidence for this comes from several sources: from human self-report, when able or unable to consummate a strong motivation; from neuroscience studies showing that the forebrain regions central to the motivational control of behaviour are involved in feelings of reward (animals will lever press to have these brain regions electrically stimulated, and both animals and humans will work to stimulate them with recreational drugs); and from findings that animals will avoid frustrating situations if they can (for more informa-

[AU 1] tion see Dawkins, 1990; Rolls, 1999, 2007). Further evidence comes from ethological studies showing that anxiety-reducing drugs reduce the behavioural consequences of frustration (this is described in more detail in Section 7.2.2), including pacing in hens (Duncan and Wood-Gush, 1974) and displacement activities in primates (Maestripieri et al., 1992). These links with emotion are why satisfying motivations is crucial for animal welfare.

Concerns that inabilities to perform natural behaviour compromise welfare are therefore to a large extent concerns about unsatisfied motivations: that animals are frustrated - with the negative emotions that this involves - if captive conditions either lack the right stimuli or substrates, or are too cramped and physically constraining, to enable consummatory behaviours. As Dawkins

[AU 1] (1988) summarizes:
Suffering [is] caused by the absence of certain conditions, where the animal is motivated to perform a behaviour but unable to perform it because of physical restraint or lack of suitable stimuli.

Next, we consider how frustration that is welfare compromising is identified.

\subsubsection{Research methods for identifying motivational frustration}

Experimental techniques for frustrating strong motivations include exposing hungry animals either to situations in which they have learned to expect food but it is unexpectedly withheld, or to food that they can detect but not obtain. By inducing frustration in a controlled way, such protocols allow its effects to be characterized and catalogued. As already mentioned, frustration is aversive, and so escape attempts often occur, along with distress signals (olfactory and/or vocal; see Table 7.1). Other typical behavioural reactions include repeated attempts to eat the absent or inaccessible food, aggression (if housed with a conspecific), and apparently irrelevant 'displacement activities' like briefly drinking, preening, grooming or self-touching. As Hinde (1970) summarizes for the frustrated animal:

Its behaviour may take a number of forms. One possibility is the appearance of investigatory activity or trial-and-error ... Another is a response to the normally inadequate stimulus situation, making possible the completion of the sequence albeit possibly in a non-functional manner. In other cases, the animal may show ... displacement or aggressive behaviour.

Duncan and Wood-Gush (1972) further showed that the escape attempts of frustrated hens develop into sustained, repetitive, stereotyped pacing, with more recent studies confirming that sustained repetitions of frustration responses underlie several forms of stereotypic behaviour. For example, the motor patterns involved in feather plucking by caged hens are morphologically identical to foraging pecks, while bar chewing by laboratory mice develops from repeated escape attempts (for more on stereotypic behaviour see Latham and Mason, in press, and Chapter 9). Frustration typically also induces physiological effects, especially sympathetic responses such as elevated blood pressure, and corticosteroid release by the adrenal cortex (see Table 7.1). 
Table 7.1. Effects of motivational frustration, as modified from Papini (2003), with supplementary examples from other papers.

\begin{tabular}{|c|c|c|}
\hline $\begin{array}{l}\text { Effect of frustration as } \\
\text { summarized by Papini (2003) }\end{array}$ & $\begin{array}{l}\text { Species (from } \\
\text { Papini, 2003) }\end{array}$ & Supplementary examples from other papers \\
\hline $\begin{array}{l}\text { Displacement activities: } \\
\text { polydipsia (excess drinking); } \\
\text { increased eating in sexually } \\
\text { frustrated animals }\end{array}$ & Rats & $\begin{array}{l}\text { Object manipulation and self-scratching increase in } \\
\text { orang-utans playing a frustrating computer game } \\
\text { (Elder and Menzel, 2001). Self-preening increases in } \\
\text { food-frustrated hens (Duncan and Wood-Gush, 1974), } \\
\text { as does oral manipulation of objects and pen mates } \\
\text { in food-frustrated pigs (Lewis, 1999). Displacement } \\
\text { drinking and self-scratching increase in male rats } \\
\text { exposed to oestrous females that they cannot reach } \\
\text { (Hansen and Drake af Hagelsrum, 1984) }\end{array}$ \\
\hline Aggression & Rats, pigs and humans & $\begin{array}{l}\text { Aggressive pecks and 'running attacks' increase in hens } \\
\text { frustrated of access to food or water (Haskell et al., 2000) }\end{array}$ \\
\hline $\begin{array}{l}\text { Escape/avoidance responses } \\
\text { and increased activity levels }\end{array}$ & Rats and humans & $\begin{array}{l}\text { Food- or water-frustrated hens pace (Duncan and } \\
\text { Wood-Gush, 1974; Haskell et al., 2000). Food-frustrated } \\
\text { pigs become more active (Lewis, 1999), and food/water- } \\
\text { frustrated hens spend more time away from the test arena, } \\
\text { becoming reluctant to approach it (Haskell et al., 2000) }\end{array}$ \\
\hline $\begin{array}{l}\text { Calling (crying/ultrasonic } \\
\text { vocalisations) }\end{array}$ & $\begin{array}{l}\text { Humans (crying) and } \\
\text { rats (ultrasound) }\end{array}$ & $\begin{array}{l}\text { 'Gakel' calls increase in hens frustrated from obtaining } \\
\text { food, water, a dust bath or nesting pre-lay (Zimmerman } \\
\text { et al., 2000) }\end{array}$ \\
\hline Stress odour release & Rats, wood rats, gerbils & \\
\hline Corticosteroid release & Rats, monkeys & $\begin{array}{l}\text { Kawasaki and Iwasaki (1999) also found corticosterone } \\
\text { increases in rats denied food that they were expecting } \\
\text { in a runway task }\end{array}$ \\
\hline $\begin{array}{l}\text { Decreased heart rate } \\
\text { (paradoxically, as this } \\
\text { suggests parasympathetic } \\
\text { response) }\end{array}$ & Rats & $\begin{array}{l}\text { Garcia-Leon et al. (2003) report similar decreases in heart } \\
\text { rate for frustrated humans }\end{array}$ \\
\hline Increased blood pressure & Humans & \\
\hline
\end{tabular}

These studies suggest that displacement activities, and attempts to perform highly motivated behaviours that cannot be consummated, can be used to identify frustration. Highly repetitive stereotypic behaviours deriving from these activities could also be evidence of specific frustration - although these may be exacerbated by wide range of stressors, and are additionally caused by brain dysfunction (see Latham and

[AU 3] Mason in press, and Chapter 9). Physiological 'stress responses' (see Chapter 10) could also indicate frustration - although, again, not specific to frustration - occurring in other negative states (e.g. fear) and in positive states involving elevated activity (e.g. copulation). Finally, chronic frustration (as just one of many potential causes of long-term stress) may be inferred when behaviourally restrictive environments cause poor reproduction, poor or aberrant growth, and/or decreased resistance to disease, because the sustained elevation of corticosteroids and sympathetic responses, such as hypertension, compromise both health and reproduction (as reviewed by Blache et al. in Chapter 10).

Measuring preference is another way to identify strong motivations (see Chapter 11). This involves assessing whether animals will learn arbitrary operant responses such as lever pressing to perform natural behaviours; and/or making it difficult to do so (e.g. increasing the number of lever presses required to gain access, or imposing natural barriers such as gaps to squeeze though, or heavily weighted doors to push (Fig. 7.2), in order to assess motivations for various goals. Such experiments have yielded important findings. However, they are not ideal for investigating behavioural restriction, because the experiences of subjects being tested are likely to increase their motivations over those of naive animals. These 'priming effects' include the motivational consequences of: learning the reward 
(a)

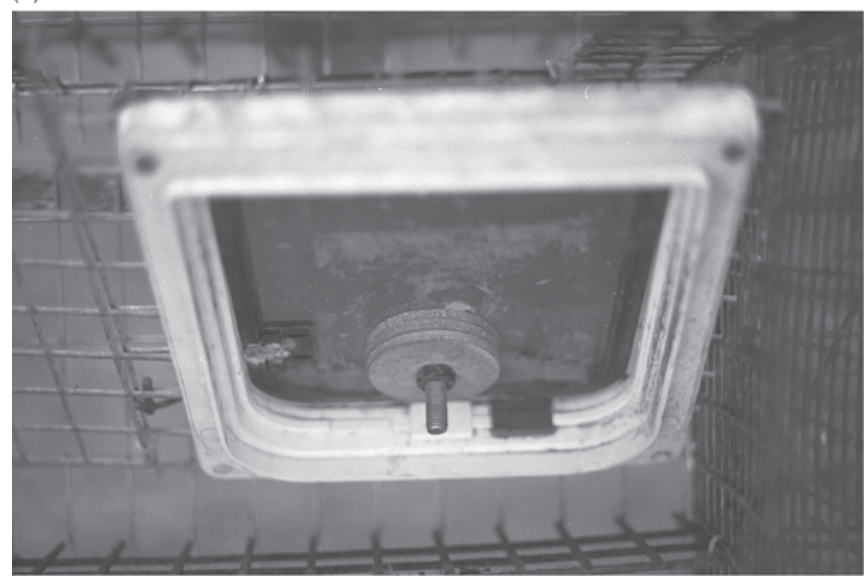

(b)

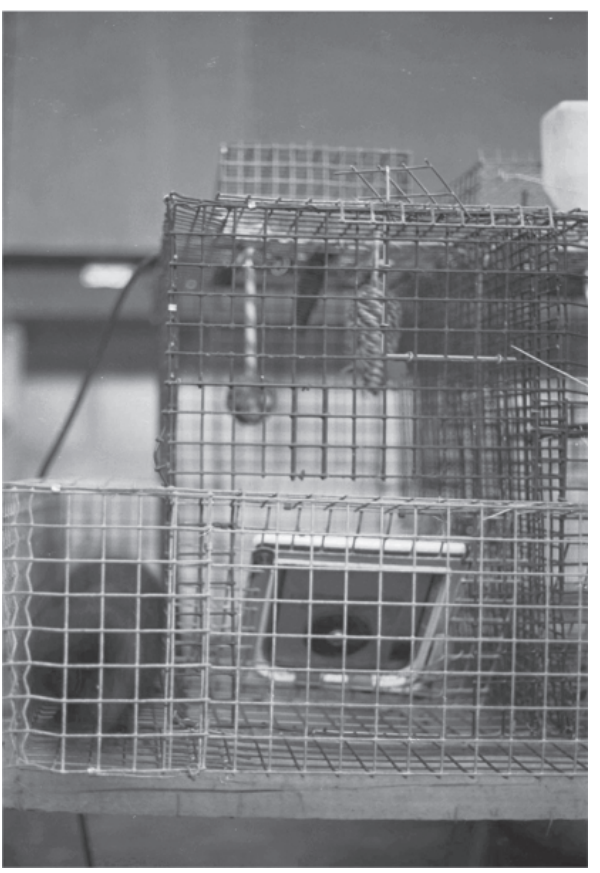

(c)

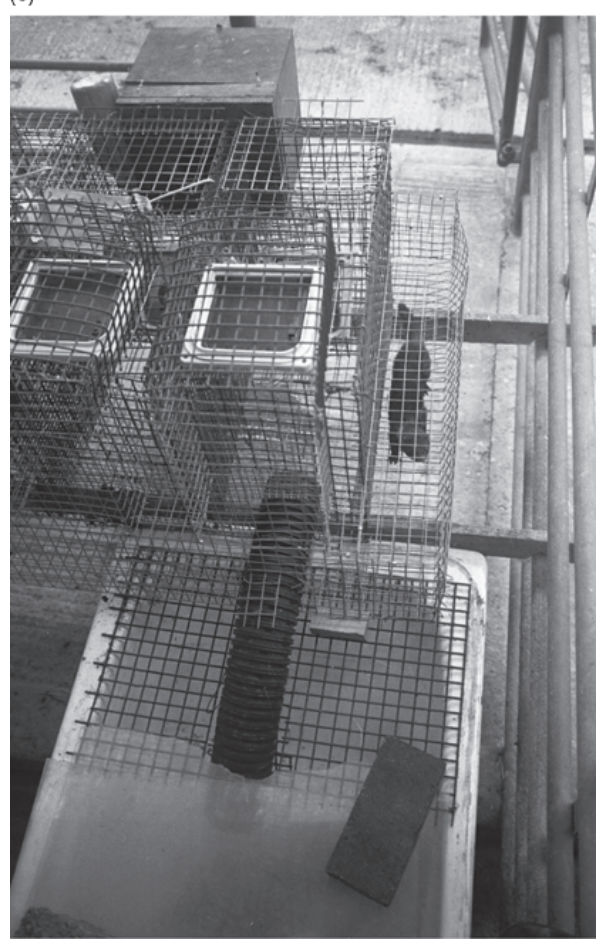

Fig. 7.2. Assessing the reward value of enrichments: an example with mink. Progressively weighting a one-way door (Fig. 7.2a) that leads to a resource can help reveal the costs that mink are prepared to pay to perform a particular behaviour, and thus their motivations to do so. In one experiment, mink would push an average maximum of $1.06 \mathrm{~kg}$ to reach cat toys they could manipulate and chew (Fig. 7.2b), but no more; and over the whole 6-week-long experiment they each pushed a total of $34 \mathrm{~kg}$ to reach these toys. In the same experiment, the mink pushed an average maximum of $1.25 \mathrm{~kg}$ to reach a bath of water in which they could head dip, paddle, swim and dive (Fig. 7.2c) - which are parts of their natural foraging behaviour (see Box 7.1); over the 6 weeks of the experiment they each pushed $130 \mathrm{~kg}$ in total [AU 1] to reach this resource. (Mason et al., 2001.) In another experiment, using differently designed weighted doors, mink pushed $2.5 \mathrm{~kg}$ to reach a water bath: not significantly different from the weight that they pushed for food in that same

[AU 1] study. (Cooper and Mason, 2000; Photos: Georgia Mason.) 


\section{Box 7.1. Water-based foraging and captive American mink (Mustela vison).}

Along the coasts, lakes and rivers of parts of northern Europe, feral American mink thrive. Despite being captive bred on fur farms for generations, they seem to retain an affinity for water; for example, Vorontsoz (1977), describing mink released near a river, says: 'An overwhelming majority ... set out towards water. Many of the tiny animals tried to bathe right there'. Mink can wreak havoc on indigenous aquatic species, sometimes swimming several kilometres to predate island seabird colonies (e.g. Nordstrom and Korpimaki 2004). (Once, unfortunately for a study cited in our nest-building section, feral mink even decimated feral hens introduced by applied ethologists to a Scottish island; Duncan et al., 1978). Baths of water in which to swim, paddle and 'head dip' also seem valued if added to caged mink pens, despite not allowing true hunting, which is the function of these behaviours in the wild. Thus, water baths increase juvenile play (Vinke et al., 2005), and mink will lever press (Hansen et al., 2005) and push weighted doors to reach them (see Fig. 7.2c). Furthermore, mink given baths, but then denied them, can show behavioural and physiological signs of frustration (though not all studies report such effects; Vinke et al., 2008). So could interacting with water be a behavioural need? Most data suggest not. In several Dutch and Danish studies across multiple farms (Vinke et al., 2008), baths failed to reduce stereotypic behaviour, or improve reproduction or immune function, compared with control mink. However, work by a Finnish group differs, with water baths reducing stereotypic behaviour on one farm (Mohaibes et al., 2008; Vinke et al., 2008). Other enrichments, such as balls, rope to chew and wire tunnels, seemed instead to far more effective (Hansen et al., 2007) One possible explanation for this pattern of results is that water-based foraging is generally not a need; it is just rewarding when it occurs, an illustration of the 'priming' effects discussed in Section 7.2.3. Another explanation is that the populations studied by different researchers truly varied - an issue that crops up in several cases in Section 7.3.2. To illustrate, in the British project

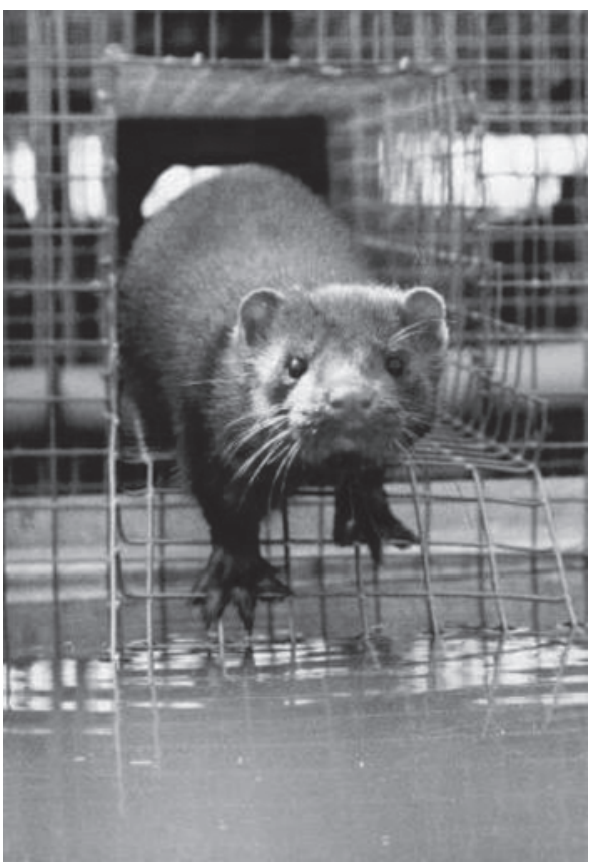

Photo: Claudia Vinke

where mink worked hard for baths (e.g. Cooper and Mason, 2000; Mason et al., 2001; and others), all subjects used baths when access was free $(58 / 58$ mink over five experiments); in contrast, only $26 / 40$ did in a Danish study finding that baths did not reduce stereotypic behaviour (Skovgaard et al., 1997). This is a significant difference $\left(\mathrm{X}^{2}=23.78, \mathrm{df}=1, p<0.0001\right.$ that could reflect genetic differences between the populations, and/or subtle differences in either the control housing or the types of baths provided. In sum, there is little doubt that mink find water-based foraging activities rewarding and enriching. However, it is currently less certain that they miss them if they have never have them - and it is even possible than some mink do while others do not. value of consummatory behaviour (as in the sexual behaviour of male rats) (Lopez and Ettenberg, 2002; Hosokawa and Chiba, 2005); and of exposure to eliciting stimuli in the test apparatus (cf. Section 7.2.1 on the role of external stimuli in motivation). So, being able to see toys, for example, increases the effort that mink are prepared to make to reach them (Fig. 7.3), and similar effects may even induce motivations that would, otherwise, probably be absent (see Fig. 7.4)! Hence, because subjects performing preference tests do not model animals living in resource-poor environments (Mendl, 1990; Mason and Warburton, 2000), preference tests can identify natural behaviours that might benefit welfare, but not whether animals without experience of such behaviours suffer frustration. 
(a) Apparatus

Cues treatment

Weighted doors to tunnels

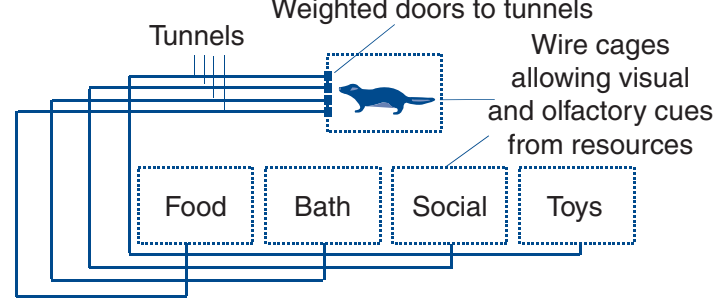

No cues treatment

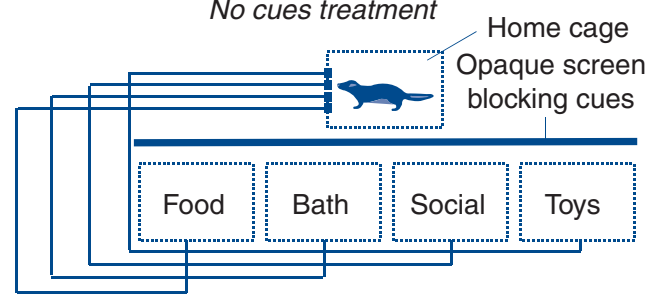

(b) Results

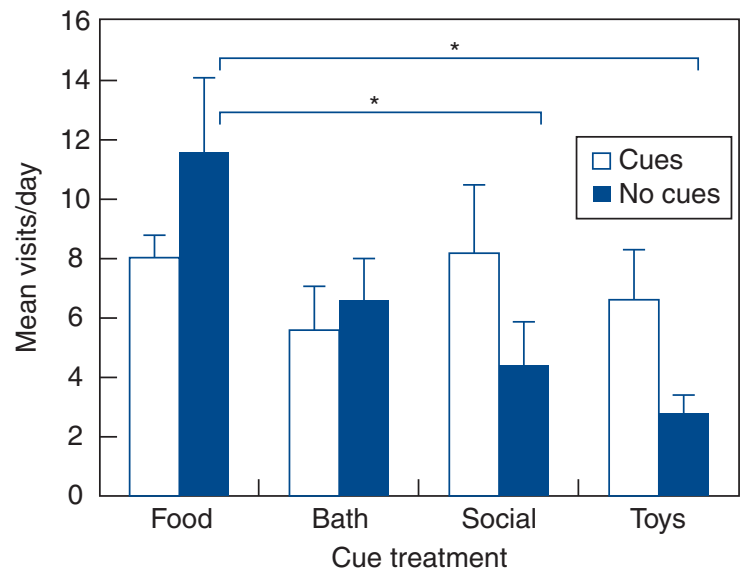

Fig. 7.3. Resource cues as a cause of the 'priming effects' that can affect animals' preferences. Mink were tested for their motivations to leave their home cages, push a weighted door and travel along a tunnel to reach either food, a water bath, social contact or a cat toy, in two different types of apparatus: one in which they could see and smell cues from these four resources at the point where they made their decisions to visit them (the 'Cues' condition), and the other in which these cues were instead screened off from them at this point ('No cues'): see Fig. 7.3a. (Redrawn by Melissa Bateson from Warburton and Mason, 2003.) Note that mink are naturally solitary, so inspecting a conspecific (as in the social contact cue) may reflect the type of defensive problem-solving shown in Fig. 7.4. As shown in Fig. 7.3b, when mink could not see the toys or social contact, they visited them less often than they visited food. This was not true in the 'Cues' condition. Being able to see toys also increased the number of visits that mink made to them each day, compared with the 'No Cues' condition; furthermore, when the access doors were made increasingly heavy to push, the mink seemed slightly more willing to pay these costs to reach toys in the 'Cues' condition than in the 'No Cues' condition. (See Warburton and Mason, 2003.)

Overall, behaviour patterns important for good welfare are therefore identified by assessing which are strongly preferred and, more importantly, which reduce behavioural and physiological signs of frustration compared with control animals unable to perform these behaviours.

\subsubsection{Types of strong behavioural motivation: from 'behavioural needs' to elicited motivations}

The potential role of external stimuli has stimulated discussions about how behaviourally restrictive housing might induce strong motivations. At one end of a spectrum of highly motivated behaviours are socalled 'behavioural needs'. These are activities that animals have instinctive, intrinsic propensities to perform whatever the environment is like; even when the physiological needs that the behaviour serves are fulfilled, and even when these behaviours are not necessary for fitness (Jensen and Toates, 1993). Hypothetical examples include: being motivated to perform natural foraging even when nutritionally sated; or prey species retaining strong motivations to hide under cover, despite being safe and not exposed to predator-like stimuli, and having been captive and not predated for generations. Other potential examples (returned to in Section 7.3.2) are motivations to nest build even when the environment provides a ready-made nest, as if performing this activity is satisfying per se. Behavioural needs are, therefore, largely driven by internal factors, and their motivations are best reduced via performance. At the other end of the spectrum of highly-motivated behaviours are activities induced by the animal's external circumstances: thus, deficits or external cues in the environment elicit the motivations. Hypothetical cases include: being highly motivated to forage 
(a)

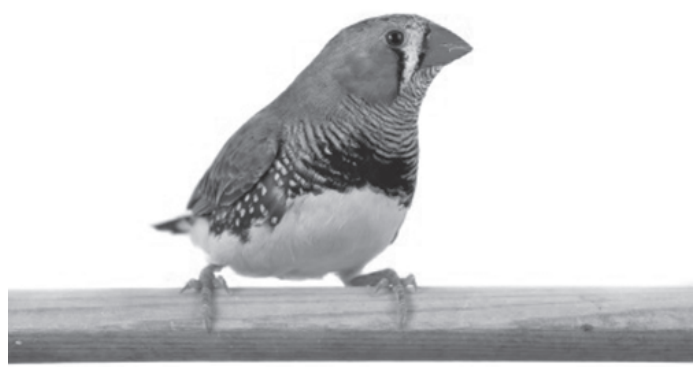

(b)

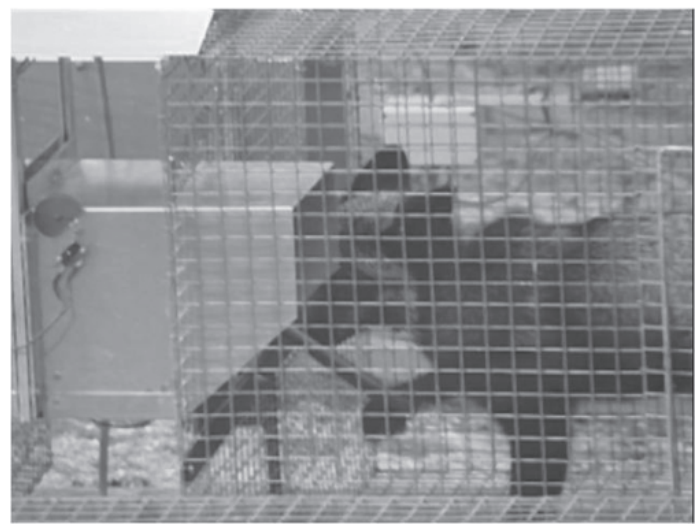

Fig. 7.4. Working to reach rivals: motivations to perform defensive problem solving. Male zebra finches (Fig. 7.4a) were placed in an apparatus in which hopping from perch to perch acted as an operant, opening a door that allowed birds see other members of their own species. It was found that a male would work harder to see a female than a male, and harder to see his own mate than another female. However, he would work hardest of all when behind the door was a threatening scenario: his own mate with another male. (McFarland, 1980; Photo: iStock Photo). Likewise, male silver foxes (a colour type of the red fox Vulpes vulpes) will perform an operant response, pulling a lever (Fig. 7.4b), to get close to other foxes. They will do this to reach vixens, who they wag their tails at - but also to reach males, who they then bare their teeth and growl at. (Hovland et al., 2006; Photo: Anne Lene Hovland).

because nutritionally deprived; the cover-seeking species mentioned above being motivated to escape from cages that offer no seclusion; or animals being motivated to hide because of external stimuli being perceived as threatening (e.g. human noise). Another case, returned to in Section 7.3, is when animals are motivated to create nests or shelters because their environments lack such structures.

This spectrum is conceptually useful for appreciating the different ways in which frustrations may be alleviated by improving housing. If strong motivations are largely internally generated, then the best way to reduce the frustration of captive animals is to allow them to perform the highly motivated behaviour (or to take the challenging approach of trying to alter the underlying physiological states of the animals). Conversely, if strong motivations are largely externally driven, then removing, providing or altering eliciting stimuli in the captive environment (or allowing animals to do so themselves) will alleviate frustration. In practice, however, it can be hard to categorize any behaviour as being strictly at one end or other of this spectrum. Indeed, as both have similarly negative implications for welfare if frustrated, and both can often be equally addressed by adding naturalistic stimuli, agonizing about such distinctions may be unimportant from a practical viewpoint; Jensen and Toates' excellent 1993 paper ('Who needs 'behavioural needs'?') argues this further.

\subsection{Frustrated Natural Behaviour and Animal Welfare: Some Examples}

Here, we first present examples of studies assessing the benefits of general social/physical 'enrichment' of the captive environment in enabling a wide range of natural behaviours. We then review in more detail experiments that manipulate just one or two aspects of that environment to pinpoint specific natural behaviours that are important for welfare. Finally, we present some natural behaviours that are known or suspected to be rewarding, but whose impact on the welfare of captive animals remains untested.

\subsubsection{General welfare effects of environmental complexity and compatibility with natural lifestyles}

Many studies have demonstrates the harms of captive environments that prevent or restrict natural behaviours. For example, being removed 
from the mother too early has lasting negative effects on many mammals, including on their stress responses, stereotypic behaviour and lifespan (reviewed by Latham and Mason, 2008). For naturally social species, isolation is also detrimental. Compared with socially housed conspecifics, isolation-housed rats show more asymmetrical body plans, indicating disrupted development (Sorenson et al., 2005), exaggerated corticosterone responses to stressors and impaired wound healing (Hermes et al., 2006), and shorter lifespans (Shaw and Gallagher, 1984; though cf. Skalicky et al., 2001); isolated horses show more stereotypic weaving (McAfee et al., 2002) and greater reactivity to acute stressors like trailer transport (Visser et al., 2008, Kay and Hall, 2009); while isolated monkeys are, again, more stereotypic (Lutz and Novak, 2003), and have elevated heart rates, increased risks of atherosclerosis, and signs of immunosuppression (Watson et al., 1998; Lilly et al., 1999, Schapiro et al., 2000). Similarly, small, physically impoverished captive environments are also often detrimental compared with those that are larger and/or 'enriched' (more naturalistic or complex). To give just a few examples, impoverished environments decrease growth rates and increase aggression in goats (Flint and Murray, 2001), decrease reproductive success and increase stereotypic behaviour in pandas (Zhang et al., 2004), and increase the fearfulness of laboratory rats, impair their abilities to heal brain injuries and reduce their longevity in old age (Passineau et al., 2001; Balcome, 2006; Bell et al., 2009). As one last illustration, from a slightly different perspective, across the Carnivora, species that are naturally wide ranging and travel large distances daily in the wild show the most stereotypic behaviour and highest infant mortality rates when caged (Fig. 7.5). Together, this large and diverse body of work dramatically demonstrates that unnatural restrictive captive conditions compromise animal welfare.

However, these studies cannot tell us whether any specific behaviour pattern is important: only that 'something about large home ranges' is important for carnivores, 'something about social contact' is important for primates, and so on. For more precision, we need studies involving fewer variables - specific environmental enrichments identifying particular natural behaviours whose performance reduces frustration. Examples of this type of finding include: that male rats live longer and are healthier into old age if they can mate (a)

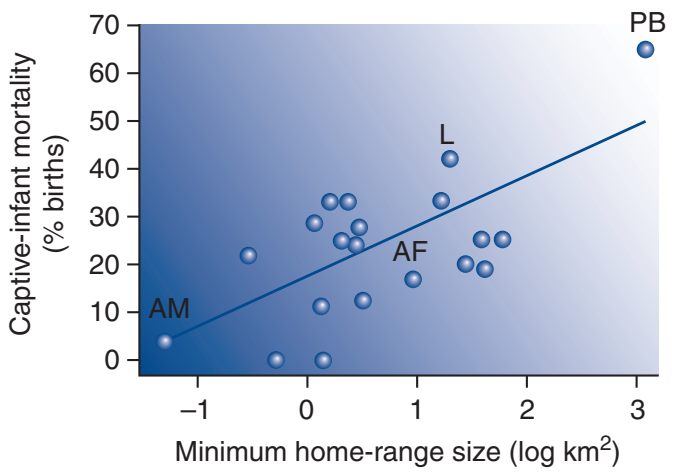

(b)

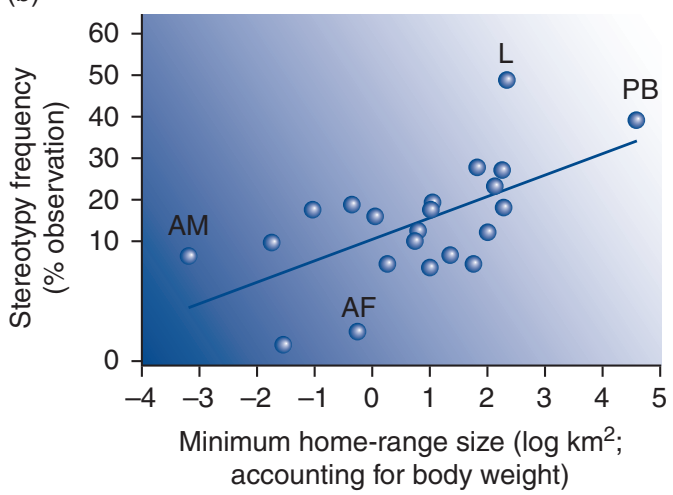

Fig. 7.5. Constraints on natural ranging predict welfare issues in carnivores. Welfare indices in captivity for species in the Order Carnivora are predicted by aspects of natural behavioural biology that are constrained by enclosure - natural home range size (shown here) and daily distance travelled. For example, the average smallest range sizes extracted from field studies of approximately 20 species predict

(a) rates of infant mortality (deaths before 30 days) in captivity, and (b) the severity of stereotypic behaviour in animals developing that behaviour. $\mathrm{PB}=$ polar bear; $\mathrm{L}=$ lion, $\mathrm{AF}=$ Arctic fox and $\mathrm{AM}=$ mink. (Clubb and Mason, 2003; Figure reprinted with permission from Nature).

[AU 6]

regularly (Salmon et al., 1990); that devices attracting foraging or foraging pecks reduce feather pecking in caged hens (Huber-Eicher and Wechsler, 1998, McAdie et al., 2005, Dixon et al., in press); and that farmed rabbits given wooden sticks to gnaw spend less time gnawing the bars of their cage, are less aggressive and grow better (Princz et al., 2007, 2009). As one final example, clouded leopards in zoos show lowered faecal 
corticoid output if provided with hiding places (Shepherdson et al., 2004).

Together, these cases show both specific and general ways in which impoverished housing should be improved (with further examples given below), and to some extent, what they reveal about the harms of behavioural restriction is obvious. However, they often leave unanswered fundamental questions about exactly how the added opportunities exert their benefits - such as whether the actual performance of the behaviour is important, or instead whether its outcome is important. In the rabbit case above, for instance, the act of gnawing itself could be the key, or instead improved tooth wear (in which case tooth trimming might be just as effective); while in the clouded leopard case, stress might be reduced by the very ability to hide, or instead by the consequences of hiding (in which case removing stressful stimuli outside the enclosure would be equally effective). Furthermore, when experiments are replicated, or potential enrichments studied by multiple research groups, subtleties and complexities often become apparent, including differences between genetically distinct populations, and large impacts of slight variations in the enrichments being offered. We deal with some of these complexities next, using, as examples, sucking by calves, belly nosing in piglets, nest building by sows and hens, and burrowing in rodents. These cases seemingly represent a spectrum from unambiguous behavioural needs through to motivations driven by deficits in the captive environment. In Box 7.1, we also discuss motivations for swimming/paddling in mink, for which a corpus of recent work reveals great variation between studies, for all or some of the reasons illustrated in the examples below.

\subsubsection{Well-studied examples of specific frustrations}

Dairy calves are typically removed from their mothers soon after birth, and then fed milk or 'milk replacer', often from buckets. These maternally deprived calves often suck protruding features of the pen and other calves' ears or prepuces - behaviour which may be accompanied by head butting resembling the udder butting of mother-reared calves. Several experiments have identified the stimuli triggering this 'non-nutritive sucking' and its apparent consequences (de

[AU 1] Passillé et al., 1993; Rushen and de Passillé,
1995; Haley et al., 1998; Veissier et al., 2002; Rushen and de Passillé, 2006). Researchers used non-nutritive rubber teats offered alongside or after a bucket of milk, and also compared calves that obtained their milk by sucking rubber teats with those having to drink directly from buckets. This allowed them to disentangle the effects of milk ingestion from the act of teat sucking itself. Non-nutritive teat sucking proved to be elicited by milk ingestion (therefore peaking after drinking milk but not water), lactose being the key component. The quantity ingested - thus nutritional satiety - seems to play little role in the termination of the behaviour which, instead, is caused by two independent processes: a timedependent decay in sucking motivation following the last intake of milk, and the very act of sucking itself. Furthermore, the behaviour seems functionally important: allowing early-weaned, bucket-fed calves to suck rubber teats increases the release of satiety hormones (Fig. 7.6); while allowing calves to suck milk from teats instead of buckets decreases their heart rates and increases heart-rate variability (signs of reduced sympathetic activation), and seems to induce calmer, more restful states (Veissier et al., 2002). This treatment also reduced the abnormal oral behaviours directed at pen mates and at the pen's bars (though, perhaps surprisingly, providing hay to eat is effective too; Haley et al., 1998). Overall then, the act of sucking seems to be a behavioural need, whose performance per se is welfare enhancing.

Other well-studied examples of behavioural frustrations come from farmed pigs. In the weeks after weaning, young piglets can similarly develop abnormal feeding-related behaviours, nosing repetitively at each others' bellies, sometimes even causing lesions. Leaving suckling piglets longer with their mothers greatly reduces their 'belly nosing' post-weaning (Widowski et al., 2003; Main et al., 2005). This, and the morphology of the abnormal behaviour, has led to hypotheses that it represents frustrated udder massage that would be directed at sows in more natural circumstances. Consistent with this, artificial nipple- or udder-like stimuli greatly reduce belly nosing in early-weaned piglets (Widowski et al., 2005; Bench and Gonyou, 2006, 2007); these stimuli seem to do this by offering the animals alternative, preferred outlets for similar nosing activities. So enrichments that only allowed rooting or chewing did not seem effective, at least 

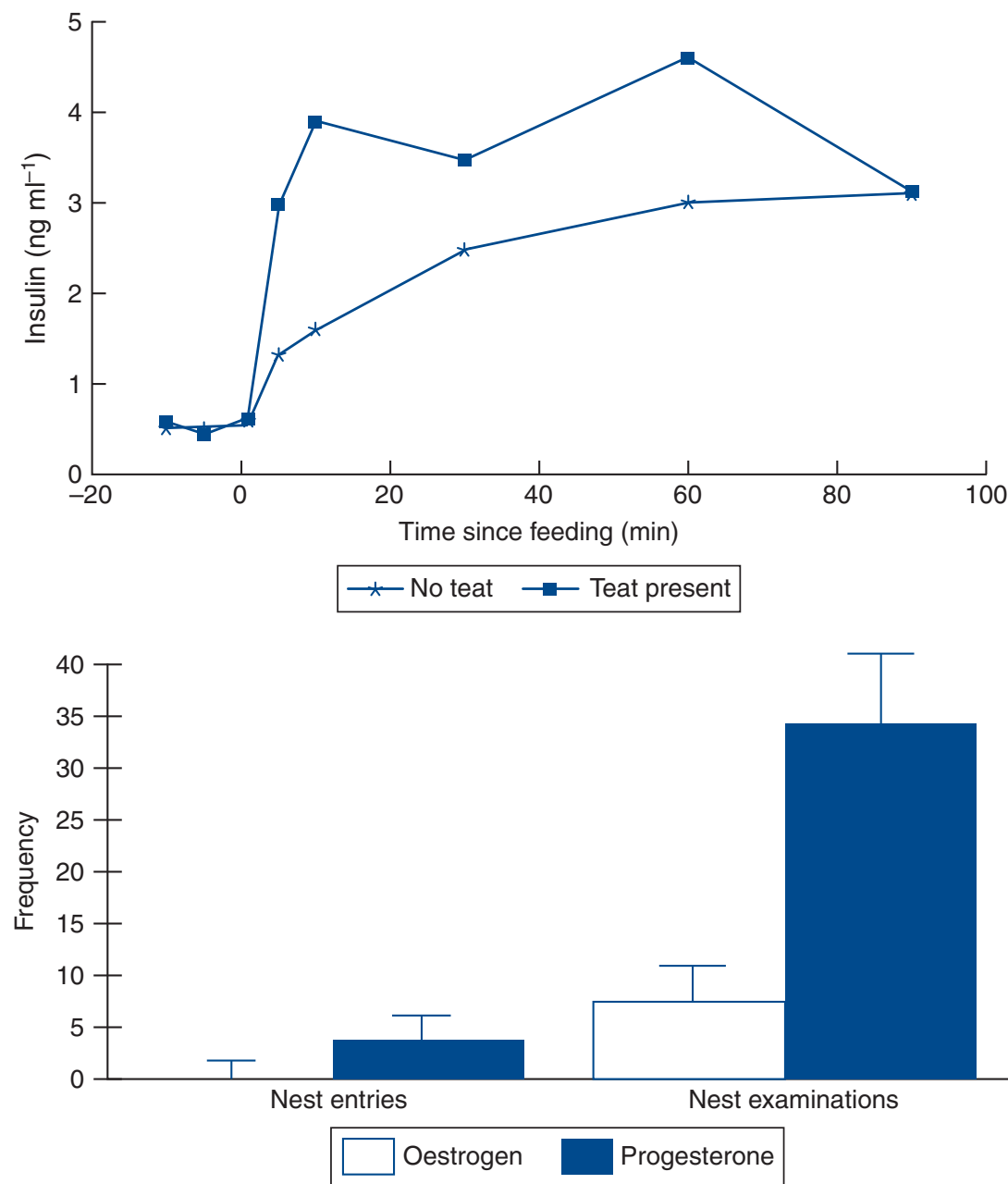

Fig. 7.6. The consequences of non-nutritive sucking by calves. Mean insulin concentrations in the hepatic portal vein of young calves after drinking milk. The calves either could or could not suck a rubber teat (which did not deliver milk) after drinking milk from a bucket. Similar effects are suggested to occur in human babies sucking pacifiers or dummies (Uvnas-Moberg et al., 1987). (Figure redrawn by Jeff Rushen and Carol Petherick, based on data in de Passillé et al., 1993).

in one study (Bench and Gonyou, 2006). However, another study - albeit using piglets with rather high levels of belly nosing - suggests that rather less 'mother-like' stimuli (a suspended tyre and rope to chew) can also reduce this behaviour, as well as making piglets less fearful of humans (Rodarte et al., 2004); and even more diverse enrichments (e.g. straw (Day et al., 2002) or working for food (Puppe et al., 2007)) can reduce belly nosing in older 'growing pigs'. Overall, it seems clear that something about premature loss of the sow and/or of suckling induces abnormal oral behaviour in newly weaned piglets, and that something about artificial stimuli that attract oro-nasal behaviour also reduces belly nosing (as well as probably improving welfare). However, it remains unknown exactly which enrichments might best compensate for this loss; or whether nosing smooth, soft materials benefits piglet physiology. The causes and welfare significance of breed differences in bellynosing severity (Bench and Gonyou, 2007) also remain unknown. 
Turning to adult pigs, females about to give birth undergo hormonal changes that both alter what they regard as suitable environments, and precipitate species-typical maternal activities such as nesting. In natural environments, pre-parturient sows seek a secluded site where they dig a depression in the earth. They then vigorously gather plant materials, which they carry to this nest site (see Fig. 2.5) and manipulate it with their snouts to construct a soft bed (Wischner et al., 2009). Little work seems to have been conducted on the motivations of sows to have particular types of nest site (unlike hens, as discussed below), but much has examined motivations to obtain nesting material, and the effects of a lack of nesting material on frustration-related variables. Sows will perform operant responses to collect straw, especially as parturition approaches (Arey, 1992), although their interest seems to vary between studies; in some, all sows offered a straw dispenser use it (Arey et al., 1991), while in others, only some do (Hutson, 1988; Widowski and Curtis, 1990). Furthermore, a lack of nesting material seems frustrating, for instance in inducing restless, stereotyped rooting and ground pawing (Wischner et al., 2009), although once again studies vary. Some experiments compare smaller bare crates with larger strawed pens, so examining effects of substrate and enclosure size combined; the crates tend to elevate the cortisol levels of preparturient females and prolong the process of parturition (Jarvis et al., 1997, 2001; Oliviero et al., 2008). Thodberg and colleagues (1999) showed similarly beneficial effects on the speed of parturition from just providing sand and nest-making materials (although another similar study found quite the opposite effect; Jarvis et al., 2004). Such sows also suckled their piglets for longer, showed less piglet crushing, and more responsiveness to piglet distress cries, than conspecifics in a similar pen with a concrete floor and no straw (Herskin [AU 8] et al., 1998, 1999).

But is it the acquiring of a nest or actually creating a nest that is the key for good sow welfare? The presence of a satisfactory nest does seem important, quite independently of the behaviour involved. Sows provided with a ready-made depression in the sand and a straw bed greatly reduce their collection of straw from a dispenser, so the pre-built nests reduce this motivation (Arey et al., 1991). Furthermore, if sows are allowed to nest build but their nests are repeatedly removed, their heart rates elevate, and by parturition their cortisol is near double that of a control group allowed to keep their nests (Damm et al., 2003). This effect occurred even though the total amount of nest building performed was similar between the two groups, again suggesting that the nest itself, not the nesting behaviour, is most important. However, not all nesting behaviour is abolished if made redundant by a ready-made nest; moving of and pawing at nesting material is unchanged, but rooting at it actually increases (Arey et al. 1991). This could mean that sows simply 'have' to perform some aspects of nesting themselves (although equally, it might just show that humans are bad at making satisfactory sow nests!). Future tests of this hypothesis could include giving sows choices between premade sow-built nests (e.g. their own from a previous parturition), and piles of raw materials; or between nests that cannot be manipulated and similar ones that can (perhaps a foam replica of a pre-made nest versus foam pieces). Pending more detailed ethological studies, for sows, the current consensus seems to be that they probably do gain motivational satisfaction from some elements of the nest-building behaviour itself. Either way, however, the take-home message is the same: it generally benefits sows to have nesting material.

Hens about to lay similarly seek secluded, enclosed nest sites, and their motivations to do so have been well studied. Thus, as Weeks and Nicol (2006) summarize, collating several authors' research:

Hens place a high value on access to discrete closed nest sites and ... their behavioural priority to access one increases the closer they get to the time of egg laying (oviposition). They are prepared to pay 'high prices' such as squeezing though narrow gaps or opening doors to gain access to nest boxes before egg laying. Moreover, hens have been found to work as hard for a nest site during the pre-laying period as they would for food following short periods of deprivation ... hens would squeeze though narrow gaps of up to $95 \mathrm{~mm}$ width (compared with an average hen body width of $120 \mathrm{~mm}$ ) to access a nest box before oviposition, but would go without food for an average of 8 hours before passing through such a small gap. Using a load-recording push door, the work rate for the nest site at 40 minutes before the expected time of oviposition was comparable to the work rate for food at 4 hours' deprivation.

This motivation is not just induced by cues from or experience with the proffered nest sites (cf. Section 7.2.4). Hens without suitable nest sites at this time exhibit 'gakel' calls apparently typifying food frustration (see Table 7.1), along with stereotypic 
pacing seemingly derived from escape attempts, and much apparent searching behaviour. They may even delay oviposition (Walker and Hughes, 1998; Yue and Duncan, 2003). A suitable nest site is, therefore, important for hen welfare.

However, this behaviour by hens again raises the question: do hens need to nest or just $a$ nest? Behavioural aspects of nesting per se have been

[AU 1] studied in feral hens (Duncan et al., 1978) as well as in caged birds, and have often been argued to be important. Once in a suitable nest site, hens show rotation movements to make a cup-shaped depression (and if litter is available they may manipulate it), and the presence of a ready-made nest does not seem to 'turn off' this behaviour. So laying hens experimentally given either a nest box of wood shavings levelled out so as to have a flat surface, or a similar box containing a nest depression made by the same hen the day before, perform similar amounts of rotating, and produce eggs similarly readily - after about 45 minutes following first entering the box (Hughes et al., 1989). This has been widely held to indicate that the very activity of nest building is motivating in its own right: a behavioural need. However, while this interpretation may be true, the findings could perhaps equally be explained in terms of bodyrotation pre-lay being simply a habit-like 'fixed action pattern', triggered by a suitable nest but not necessarily rewarding. Consistent with this view, hens offered an enclosed nest box with a ready-made, non-mouldable Astroturf surface accept this readily as a nesting location (Appleby et al., 1993), and lay soon after entering the box (c. 40 minutes; Struelens et al., 2008), suggesting that the simple non-functional nesting movements possible on Astroturf do not frustrate the hen. Furthermore, when hens are offered a choice, substrates such as peat, which allow the creation of a nest hollow and can be manipulated, seem no more preferred than artificial turf, which does not allow this. Thus, Struelens et al. (2005) found that both these nest types were greatly preferred over wire, but attracted the same number of eggs laid. In further work, peat was found to elicit longer sitting and more pecking than artificial turf but, aside from that, its behavioural effects seemed small (Struelens et al., 2008). Overall, this suggests that good captive environments must supply a suitably enclosed nest area, but as long as this is there, hens can forego true nest making itself.
Note that some variation between studies occurs on this topic too, with nest-box properties (e.g. degree of privacy) having quite strong effects on hen responses, and the types of artificial nest sites accepted as suitable also varying between strains and even between individual females (Yue and Duncan, 2003; Weeks and Nicol, 2006). The provision of unsuitable nest boxes might explain why some cages furnished with nests fail to have the benefits one might expect. Barnett et al. (2009), for example, found that providing a nest box did not reduce corticosteroid levels, nor enhance immunity, compared with control hens in barren cages - but only half to two-thirds of their experimental birds chose to lay their eggs in the provided nest boxes, compared with the 99-100\% 'approval rating' seen in other experiments (Appleby et al., 1993; Weeks and Nicol 2006).

Our last example concerns tunnel creation and digging in naturally burrowing rodents. Some elegant experiments have investigated stereotypic digging by gerbils. This abnormal behaviour is unaffected by providing loose sand in which the animals can dig (Wiedenmayer, 1996, 1997a). Instead, it is nearly abolished by the provision of a ready-made naturalistic burrow (Wiedenmayer, 1997b), in which gerbils also prefer to hide, sleep and suckle their young compared with the shelters provided in standard laboratory cages. Nonnaturalistic plastic 'burrows' have similar effects, as long as they consist of a tunnel leading to a chamber, and have opaque, rather than transparent, walls. Like a naturalistic burrow, gerbils rapidly adopt these as their preferred homes when given a choice, and stereotypic digging all but vanishes (Wiedenmayer, 1997a; Waiblinger and Konig, 2004). Such findings reveal that frustrated motivations to dig in captivity persist only when gerbils lack the natural goal of this behaviour: a burrow leading to a nest chamber. Digging per se, in contrast, does not seem to be a behavioural need.

These five well-studied cases illustrate that behavioural needs and environmental deficits can be hard to tell apart, but that both cause frustration in typical housing systems. They also generate several other 'take-home messages'. One is that enrichments that seem similar to us (e.g. different types of nest box for hens; plastic nest chambers with or without a short tunnel for gerbils) may be perceived very differently by the 
animals they are offered to. This may help to explain why studies do not always replicate each others' findings - as too may genetic differences between populations studied in different experiments (best documented for hens and piglets, but possibly widespread) help to explain the lack of replication. Finally, they also remind us that if specific frustrations cause welfare problems, we should expect equally specific enrichments to be effective. However, sometimes surprisingly, diverse enrichments can have similar effects on signs of frustration (as in both piglet belly nosing and calf sucking). Box 7.1 illustrates all these issues, using recent work on mink.

\subsubsection{And finally ...}

There are many apparently rewarding behaviours whose potential welfare impact is still unknown, and many more that remain completely uninvestigated. Thus laboratory rats will bar press for live mice to kill (Van Hemel, 1972), but whether other predators find killing reinforcing is unknown, as are any benefits to welfare (carnivore welfare rather than that of their preys'!). Hens also perform operant tasks to reach litter or straw to scratch and peck at (they may dust bath in it too; Dawkins and Beardsley, 1986; Gunnarsson et al., 2000), while pigs do likewise to gain access to peat and other materials in which they can root (Jensen and Pedersen, 2005). However, the reward value and welfare importance of many other natural foraging behaviours is still little understood (for example, whether browsers need to browse, and grazers to graze). Given the chance, laboratory mice and several species of deer mice will perform operant tasks in order to dig burrows in sand or peat (King and Weisman, 1964; Sherwin et al., 2004), but we do not know if the absence of digging opportunities - or of completed burrows as for the gerbils described above - compromises mouse welfare in standard cages. The reward value of only a few specific social behaviours have been investigated so far; being groomed was reinforcing for a rhesus monkey (Taira and Rolls, 1996), play is a reinforcer for juvenile rats (Humphreys and Einon, 1981), and female mammals in oestrus will pay costs to mate with males

[AU 1] (reviewed by Wallen, 1990). However, whether a lack of any of these is frustrating and stressful, we do not know. Opportunities to display aggressively or even to fight are also reinforcing for males, in species as diverse as chickens, Siamese fighting fish, rats and mice (Fish et al., 2002; reviewed May and Kennedy, 2009; see also Fig. 7.4b); and male chaffinches will perform a perch-hopping operant to hear the songs of other males (Stevenson-Hinde and Roper, 1975). However, yet again it is unknown whether aggression (or perhaps just winning) improves the welfare of males, or whether these findings instead merely reflect defensive motivations elicited when rivals appear to be close by. To end, among the many further unanswered questions are whether captive horses need to gallop, captive cheetahs to sprint, captive beavers to make dams, caged birds need to fly or, as discussed below, whether any animals experience 'boredom' caused by the sheer lack of anything relevant to do at all.

\subsection{Do Impoverished Environments Cause Boredom in Animals?}

For humans, the frustration of specific natural behaviour patterns is not the only problem caused by impoverished environments. Human boredom arises when there is 'nothing to do' (i.e. there is an absence of behavioural opportunities) or when a monotonous environment offering little chance for behavioural diversification makes us 'tired of doing the same thing' (Larson and Richards, 1991). Humans find boredom aversive (Harris, 2000), and it can be seen as a form of frustration in that it is a thwarting of a motivation to 'do something else' or to explore something new.

If animals can similarly experience boredom like humans, then unlike frustrations arising from specific thwarted motivations, boredom will arise when animals are not motivated to perform any of the behaviours that are possible in their environments because these are too limited or monotonous. Furthermore, this will cause poor welfare. The question of whether boredom is truly a welfare issue for behaviourally restricted animals can be approached from three angles: Is boredom a problem for humans who live in conditions similar to those of captive animals?; Do captive animals seek novelty and diversity generally, rather than just seeking to satisfy specific motivations?; and Do animals in environments likely to induce boredom show responses similar to those of bored humans?

To address the first question, there are ample reports that boredom is a profound problem for 
human prisoners. For example, a prisoner quoted in Wahidin (2006) says:

The boredom and the isolation ... every day is the same. It is just dreadful. Every single day is the same. It drives you mad! ... every single day is just actually the same as the day before. Your meals are the same time. Everything. Oh it's horrible.

[AU 1] Bracke et al. (2006) attribute boredom in human prisoners to 'routinized activities lacking intrinsic meaning and lacking emphasis on task completion'. Experimentally induced sensory deprivation similarly induces aversive states. As Berlyne (1960) reports:

Sensory deprivation becomes aversive when internal factors cause a rise in arousal and the lack of stimulation renders the cortex incapable of keeping arousal within bounds"; "Lying motionless in a quiet dark room ... is extremely trying ... when one is healthy and has had enough sleep.

Normal everyday life can also induce boredom if monotonous; for example, in 'Bleak House', Dickens (1853) describes the importance of irrelevant repetition and lack of novelty:

My Lady Dedlock has been bored to death. Concert, assembly, opera, theatre, drive, nothing is new to my Lady under the worn-out heavens ... They meet again at dinner - again, next day - again, for many days in succession. Lady Dedlock is ... terribly liable to be bored to death.

Routine, irrelevant repetition and monotonous stimuli - the causes of boredom in humans - arguably characterize many captive animals' lives, which leads us to the second question. Boredom will only be problematic if animals, like humans, seek novelty and diversity generally, rather than just the satisfaction of specific motivations. In fact, many species will work to obtain sensory or exploratory experiences, at least when housed in research laboratories or zoos. Here, they will invest time and energy in manipulating novel objects without any obvious rewards; for example, primates perform operant responses to obtain stones, sand or other manipulable objects, and rats - which are usually averse to light - will lever press to access flashing lights in the absence of other stimulation (reviewed Berlyne, 1960). Animals may even forgo usually favoured food items in preference for less favoured, but more novel, items. For example, rats and hamsters fed chow containing a preferred non-nutritive flavour for several days will discard this in favour of a novel chow containing a less preferred flavour (Galef and
Whiskin, 2005). Some animals in barren conditions also seem to 'sensation seek' (cf. Zuckerman, 1994), seeking out almost any stimuli that increase arousal; individually housed rats even self-administer corticosterone, delivered intraperitoneally via a catheter, and also to some extent the saline control (which slightly increases endogenous corticosterone production) (Piazza et al., 1993). Such behaviours are most common in neophilic (novelty-seeking) species, almost by definition (Stevenson, 1983; Kirkden, 2000), and are sometimes assumed most evident in species with greater cognitive flexibility (WoodGush et al., 1983). As well as species differences, individuals differ in motivations for stimulation. For example, the rats showing the highest propensity to self-administer corticosterone were also the most exploratory (Piazza et al., 1993), suggesting a common 'sensation-seeking' underlying mechanism. Overall, it is thus possible that at least some animals have behavioural needs for stimulation. For such animals, behavioural restriction may well frustrate general, non-specific motivations for sensory or cognitive feedback.

The third, most difficult, question is whether captive animals actually show responses consistent with boredom. Human boredom and proneness to boredom (reviewed by Berlyne, 1960; Fazzi et al., 1999; Newberry and Duncan, 2001) are associated with signs of poor welfare, including depression and lethargy, social dysfunction, aggression and cognitive deficits. They are also associated with 'sensationseeking' behaviours like dangerous driving, drug abuse and gambling. Finally, boring situations induce repetitive behaviours (e.g. knee joggling, hair twirling and other 'fidgets' as akin to displacement activities, along with more stereotypic pacing, rocking and similar), which could reflect frustration, be attempts to generate stimulation, or both. Turning to animals, neophilic species such as pigs spend longer interacting with novel objects if kept in more barren environments than do pigs in more complex environments, indicating that barren environments increase urges to seek stimulation (reviewed by Wood-Gush et al., 1983). Also, rats kept individually in standard cages showed significantly greater consumption of self-administered morphine than those housed socially in a large, highly enriched pen (Alexander, 1978). More studies are needed to see if such effects are widespread, and what exactly are their causes. For captive animals not offered novelty in this way, boredom is already often suggested as a cause of 'depression', 'apathy', or abnormal and 
destructive behaviours (e.g. reduced activity, Dawkins, 2001; tail chasing in dogs, Hartigan, 2000; primate stereotypies, Tarou et al., 2005) although these hypotheses have not been directly tested. Stereotypic behaviours caused or exacerbated by insufficient stimulation generally, rather than by one specific frustration, should be alleviated by almost any 'environmental enrichment' that offers stimulation. Some indirect evidence for this comes from meta-analyses of the effects of enrichments in zoos (Shyne, 2006; Swaisgood and Shepherdson 2006) showing that the stereotypies of zoo animals can be reduced by a diverse array of enrichments (e.g. polar bear pacing can be reduced by food puzzles, olfactory stimuli or physical toys alike). Swaisgood and Shepherdson (2006) suggest that:

in the most extreme situations, one might argue that 'something, anything' added to a stimulus-poor environment may have equally meaningful effects on stereotypy (and perhaps other indices of welfare)

although they admit some equally plausible alternative explanations.

Together these reports are consistent with boredom being an animal welfare problem. However, more evidence is needed to demonstrate true parallels between human and animal responses to monotonous environments and, thus, true boredom, because to date most consistent findings are rather circumstantial, post hoc, or open to alternative explanations.

\subsection{Conclusions}

- A vast amount of research demonstrates that, compared with standard barren cages, socially naturalistic and/or physically complex environments yield behavioural and physiological benefits to animals that indicate reduced stress.

- Well-fed, physically healthy animals do not then automatically have good welfare, if - as is still the case for many species in many husbandry systems - their cages are small, impoverished or otherwise behaviourally restrictive.

- Frustrating specific strongly motivated behaviours is one potential cause of welfare problems in barren environments. Strong specific motivations may be induced by the presence of certain external stimuli, the lack of appropriate resources in the environment and/or intrinsic requirements to perform certain natural activities ('behavioural needs').
- Research has also identified a diverse array of natural behaviours that animals prefer to perform when they can, but whose absence has an uncertain or unknown effect on the welfare of animals who have never experienced these behaviours (mouse killing by rats and swimming by mink being two examples).

- When the welfare implications of specific frustrations are investigated by different research groups working in different ways and in different locations, findings sometimes vary. This could reflect subtle (to us) differences between the behavioural opportunities offered to the animals, subtle (to us) differences in the control environments where these are denied, genetic differences between populations or non-specific effects like boredom.

- Such findings potentially open up future possibilities of improving welfare by selective breeding and genetic selection or even genetic engineering (cf. Chapter 16), and suggest that offering captive animals a range of resources or substrates rather than one single type may best allow the flexible accommodation of their motivations.

- In addition to specific behavioural frustrations, more general, non-specific boredom is also a real possibility, especially for neophilic species and individuals. For example, sometimes rather dissimilar enrichments, which appear as outlets for quite different motivations, can have surprisingly similar effects on the abnormal behaviour and stress physiology of animals. This suggests that 'cognitive enrichments' (cf. Manteuffel et al., 2009) could be a valuable way to improve animal welfare, enhancing it via cognitive stimulation regardless of whether the tasks or the actions involved resemble anything natural.

\section{Acknowledgements}

With thanks to Joy Mench for her help and patience as an editor, and to the University of Guelph Animal Behaviour and Welfare Group, especially Ian Duncan, Kati Poczta, Kim Sheppard, Stephanie Yue-Cottee, Stephanie Torrey and Tina Widowski.

\section{References}

Appleby, M.C., Smith, S.F. and Hughes, B.O. (1993) Nesting, dust bathing and perching by laying hens in cages: effects of design on behavior and welfare. British Poultry Science 34, 835-847. 
Arey, D.S. (1992) Straw and food as reinforcers for prepartal sows. Applied Animal Behaviour Science 33, 217-226.

Arey, D.S., Petchey, A.M. and Fowler, V.R. (1991) The preparturient behaviour of sows in enriched pens and effect of pre-formed nests. Applied Animal Behaviour Science 31, 61-68.

Balcome, J.P. (2006) Laboratory environments and rodents' behavioural needs: a review. Laboratory Animals 40, 217-235.

Bell, J.A., Livesey, P.F. and Meyer, J.F. (2009) Environmental enrichment influences survival rates and enhances exploration and learning but produces variable responses to the radical maze in old rats. Developmental Psychobiology 51, 564-578.

Barnett, J.L., Tauson, R., Downing, J.A., Janardhana, V., Lowenthal, J.W., Butler, K.L. and Cronin, G.M. (2009) The effect of a perch, dust bath and nest bow, either alone or in combination as used in furnished cages on the welfare of laying hens. Poultry Science 88, 456-470.

Bench, C.J. and Gonyou, H.W. (2006) Effect of environmental enrichment at two stages of development on belly nosing in piglets weaned at fourteen days of age. Journal of Animal Science 84, 3397-3403.

Bench, C.J. and Gonyou, H.W. (2007) Effect of environmental enrichment and breed line on the incidence of belly nosing in piglets weaned at 7 and 14 days-ofage. Applied Animal Behaviour 105, 26-41.

Berlyne, D.E. (1960) Conflict, Arousal, and Curiosity. McGraw-Hill, New York.

Blake, W. (1863) Auguries of innocence. In: Rossetti, D.G. (ed.) Poems.

Blom, H.J.M., Baumans, V., Van Vorstenbosch, C.J.A.H.V., Van Zutphen L.F.M. and Beynen, A.C. (1993) A preference test with rodents to assess housing conditions. Animal Welfare 2, 81-87.

Brambell Committee (1965) Report of the Technical Committee to Enquire into the Welfare of Animals Kept under Intensive Husbandry Systems. Command

[AU 11] Paper 2836, Her Majesty's Stationery Office, London.

Clubb, R. and Mason, G. (2003) Captivity effects on wide-ranging carnivores. Nature 425, 473-474.

Clubb, R. and Mason, G. (2007) Natural behavioural biology as a risk factor in carnivore welfare: how understanding species differences could help zoos redesign enclosures. Applied Animal Behaviour Science 102, 303-328.

[AU 12]

Damm, B.I., Pedersen, L.J., Marchant-Forde, J.N. and Gilbert, C.L. (2003) Does feed-back from a nest affect periparturient behaviour, heart rate and circulatory cortisol and oxytocin in gilts? Applied Animal Behaviour Science 83, 55-76.

Dawkins, M.S. (2001) How can we recognize and assess good welfare? In: Broom, D.M. (ed.) Coping with Challenge: Welfare in Animals including Humans. Dahlem University Press, Berlin, pp. 63-78.
Dawkins, M.S. and Beardsley, T. (1986) Reinforcing properties of access to litter in hens. Applied Animal Behaviour Science 15, 351-364.

Day, J.E.L., Burfoot, A., Docking, C.M., Whitaker, X., Spoolder, H.A.M. and Edwards, S.A. (2002) The effects of prior experience of straw and the level of straw provision on the behaviour of growing pigs. Applied Animal Behaviour Science 76, 189-202.

de Passillé, A.M.B., Christopherson, R. and Rushen, J. (1993) Nonnutritive suckling by the calf and postprandial secretion of insulin, CCK, and gastrin. Physiology and Behaviour 54, 1069-1073.

de Passillé, A.M.B. and Rushen, J. (2006) What components of milk stimulate suckling in calves? Applied Animal Behaviour Science 101, 243-252.

Dickens, C. (1853) Bleak House. Bradbury and Evans, London.

Duncan, I.J.H. and Wood-Gush, D.G.M. (1974) The effect of a rauwolfia tranquillizer on stereotyped movements in frustrated domestic fowl. Applied Animal Ethology 1, 67-76.

Elder, C.M. and Menzel, C.R. (2001) Dissociation of cortisol and behavioral indicators of stress in oragnutan (Pongo pygmaeus) during a computerized task. Primates 42, 345-357.

FAWC (Farm Animal Welfare Council) (2009) Five Freedoms. Available at: http://www.fawc.org.uk/ freedoms.htm (accessed July 2010).

Fazzi, E., Lanners, J., Danova, S., Ferrarri-Ginevra, O., Gheza, C., Luparia, A., Balottin, U. and Lanzi, G. (1999) Stereotyped behaviours in blind children. Brain Development 21, 522-528.

Fish, E.W., de Bold, J.F. and Miczek, K.A. (2002) Aggressive behaviour as a reinforce in mice: activation by allopregnanolone. Psychopharmacology 163, 459-466.

Flint, M. and Murray, P.J. (2001) Lot-fed goats - the advantages of using an enriched environment. Australian Journal of Experimental Agriculture 41, 473-476.

Fraser, D. and Duncan, I.J.H. (1998) 'Pleasures', 'pains' and animal welfare: toward a natural history of affect. Animal Welfare 7, 383-396.

Galef, B.G. Jr and Whiskin, E.E. (2005) Differences between golden hamsters (Mesocricetus auratus) and Norway rats (Rattus norvegicus) in preference for the sole diet that they are eating. Journal of Comparative Psychology 119, 8-13.

Gunnarsson, S., Matthews, L.R., Forste, T.M. and Temple, W. (2000) The demand for straw and feathers as litter substrates by laying hens. Applied Animal Behaviour Science 65, 321-330.

Haley, D.B., Rushen, J., Duncan, I.J.H., Widowski, T.M. and de Passillé, A.M. (1998) Effects of resistance to milk flow and the provision of hay on nonnutritive sucking by dairy calves. Journal of Dairy Science 81, 2165-2127.

Hansen, S. and Drake af Hagelsrum, L.J. (1984) Emergence of displacement activities in the male-rat 
following thwarting of sexual-behavior. Behavioral Neuroscience 98, 868-883.

Hartigan, P.J. (2000) Compulsive tail chasing in the dog: a mini-review. Irish Veterinary Journal 53, 261-264.

Haskell, M., Coerse, N.C.A. and Forkman, B. (2000) Frustration-induced aggression in the domestic hen: the effect of thwarting access to food and water on aggressive responses and subsequent approach tendencies. Behaviour 137, 531-546.

Helme, A.E. (2008) A comparison of intelligence in corvids and apes: implications for animal welfare. $\mathrm{PhD}$

[AU 12] thesis, The University of Cambridge, Cambridge, UK.

Hermes, G.L., Rosenthal, L., Montag, A. and McClintock, M.K. (2006) Social isolation and the inflammatory response: sex differences in the enduring effects of a prior stressor. American Journal of Physiology Regulatory, Integrative and Comparative Physiology 290, 273-282.

Hinde, R.A. (1970) Animal Behaviour: A Synthesis of Ethology and Comparative Psychology, 2nd edn. McGraw-Hill Kogakusha, Tokyo.

Hobbes, T. (1651) Leviathan or The Matter, Forme and Power of a Common Wealth Ecclesiasticall and Civil. Andrew Crooke and William Cooke, London.

Hosokawa, N. and Chiba, A. (2005) Effects of sexual experience on the conspecific odor preference and estrous odor-induced activation of the vomeronasal projection pathway and the nucleus accumbens in male rats. Brain Research 1066, 101-108.

Hovland, A.L., Mason, G., Bøe, K.E., Steinham, G. and Bakken, M. (2006). Evaluation of 'maximum price paid' as an index of motivational strength for farmed silver foxes (Vulpes vulpes). Applied Animal Behaviour Science 100, 258-279.

Huber-Eicher, B. and Wechsler, B. (1998) The effect of quality and availability of foraging materials on feather pecking in laying hen chicks. Animal Behaviour 55, 861-873.

Hughes, B.O. and Duncan, I.J.H. (1988) The notion of ethological 'need', models of motivation and animal welfare. Animal Behaviour 36, 1696-1707.

Hughes, B.O., Duncan, I.J.H., and Brown, M.F. (1989) The performance of nest building by domestic hens: is it more important than the construction of a nest? Animal Behaviour 37, 210-214.

Hughes, R.N. (1997) Intrinsic exploration in animals: motives and measurement. Behavioural Processes 41, 213-226.

[AU 12]

Humphreys, A.P. and Einon, D.F. (1981) Play as a reinforcer for maze-learning in juvenile rats. Animal Behaviour 29, 259-270.

Hutson, G.D. (1988) Do sows need straw for nest building? Australian Journal of Experimental Agriculture 28, 187-194.

Jarvis, S., Lawrence, A.B., McLean, K.A., Deans, L.A., Chirnside, J. and Calvert, S.K. (1997) The effect of environment on behavioural activity, ACTH, betaendorphin and cortisol in pre-farrowing gilts. Animal Science 65, 465-472.

Jarvis, S., Van der Vegt, B.J., Lawrence, A.B., McLean, K.A., Deans, L.A., Chirnside, J. and Calvert, S.K. (2001) The effect of parity and environmental restriction on behavioural and physiological responses of pre-parturient pigs. Applied Animal Behaviour Science 71, 203-216.

Jarvis, S., Reed, B.T., Lawrence, A.B., Calvert, S.K. and Stevenson, J. (2004) Peri-natal environmental effects on maternal behaviour, pituitary and adrenal activation and the progress of parturition in the primiparous sow. Animal Welfare 13, 171-181.

Jensen, M.B. and Pedersen, L.J. (2007) The value assigned to six different rooting materials by growing pigs. Applied Animal Behaviour Science 108, 31-44.

Jensen, P. and Toates, F.M. (1993) Who needs 'behavioural needs'? Motivational aspects of the needs of animals. Applied Animal Behaviour Science 37, 161-181.

Kawasaki, K. and Iwasaki, T. (1997) Corticosterone levels during extinction of runway response in rats. Life Sciences 61, 1721-1728.

Kay, R. and Hall, C. (2009) The use of a mirror reduces isolation stress in horses being transported by trailer. Applied Animal Behaviour Science 116, 237-243.

King, J.A. and Weisman, R.G. (1964) Sand digging contingent upon bar pressing in deermice. Animal Behaviour 12, 446-450.

Kirkden, R.D. (2000) Assessing motivational strength and studies of boredom and enrichment in pigs. PhD thesis. University of Cambridge, Cambridge, UK.

Latham, N. and Mason, G.J. (2008). Maternal separation and the development of stereotypies: a review. Applied Animal Behaviour Science 110, 84-108.

Lewis, N.J. (1999) Frustration of goal-directed behaviour in swine. Applied Animal Behaviour Science 64, 19-29.

Lilly, A.A., Mehlman, P.T. and Higley, J.D. (1999) Trait-like immunological and haematological measures in female rhesus across varied environmental conditions. American Journal of Primatology 48, 197-223.

Lopez, H.H. and Ettenburgh, A. (2002) Exposure of female rats produces differences in c-fos inductions between sexually-naïve and experienced male rats. Brain Research 947, 57-66.

Lutz, C., Well, A. and Novak, M. (2003) Stereotypic and self-injurious behavior in rhesus macaques: a survey and retrospective analysis of environment and early experience. American Journal of Primatology 60, $1-15$.

Maestripieri, D., Schino, G., Aureli, F. and Troisi, A. (1992) A modest proposal: displacement activities as an indicator of emotions in primates. Applied Animal Behaviour Science 44, 967-979.

Main, R.G., Dritz, S.S., Tokach, MD., Goodband, R.D., Nelssen, J.L. and Loughlin, T.M. (2005) Effects of 
weaning age on postweaning belly-nosing behaviour and umbilical lesions in a multi-site production system. Journal of Swine Health and Production 13, 259-264.

Manteuffel, G., Langbein, J. and Puppe, B. (2009) From operant learning to cognitive enrichment in farm animal housing: bases and applicability. Animal Welfare Science 18, 87-95.

Mason, G. (2006) Stereotypic behaviour: fundamentals and applications to animal welfare and beyond. In: Mason, G. and Rushen, J. (eds) Stereotypic Behaviour in Captive Animals: Fundamentals and Applications to Welfare. $\mathrm{CAB}$ International, Wallingford, UK, pp.

[AU 12] 325-356.

Mason, G. and Bateson, M. (2009) Motivation and the organization of behaviour. In: Jensen, P. (ed.) The Ethology of Domesticated Animals, 2nd edn. CAB International, Wallingford, UK, pp. 38-56.

May, M.E. and Kennedy, C.H. (2009) Aggression as positive reinforcement in mice under various ratio- and time-based reinforcement schedules. Journal of Experimental Analysis of Behavior 91, 185-196.

McAdie, T.M., Keeling, L.J., Blokhuis, H.J. and Jones, R.B. (2005) Reduction in feather pecking and improvement of feather condition with the presentation of a string device to chickens. Applied Animal Behaviour Science 93, 67-80.

McAfee, L.M., Mills, D.S. and Cooper, J.J. (2002) The use of mirrors for the control of stereotypic weaving behaviour in the stabled horse. Applied Animal Behaviour Science 78, 159-173.

[AU 14] McFarland, D. (1987) The Oxford Companion to Animal Behaviour. Oxford University Press, Oxford, UK.

Mendl, M. (1990) Developmental experience and the potential for suffering: does "out of experience" mean "out of mind?" Behavioral and Brain Science 13, 28-29.

Newberry, A.L. and Duncan, R.D. (2001) Roles of boredom and life goals in juvenile delinquency. Journal of Applied Social Psychology 31, 527-541.

Nithianantharajah, J. and Hannan, A.J. (2006) Enriched environments, experience-dependent plasticity and disorders of the nervous system. Nature Reviews

[AU 12] $\begin{aligned} & \text { Neuroscience 7, 697-709. } \\ & \text { Oliviero, C., Heinonen, M., Valros, A., Häilli, O. and }\end{aligned}$ Peltoniemi, O.A.T. (2008) Effect of the environment on the physiology of the sow during late pregnancy, farrowing and early lactation. Animal Reproduction Science 105, 365-377.

Papini, M.R. (2003) Comparative psychology of surprising non-reward. Brain, Behavior and Evolution 62, 83-95.

Passineau, M.J., Green E.J. and Dietrich, W.D. (2001) Therapeutic effects of environmental enrichment on cognition functions and tissue integrity following severe traumatic brain injury in rats. Experimental Neurology 168, 373-384.
Petherick, J.C., Seawright, E. and Waddington, D. (1993) Influence of quantity of litter on nest box selection and nesting-behavior of domestic hens. British Poultry Science 34, 857-872.

Piazza, P.V., Deroche, V., Deminiere, J.M., Maccari, S., Le Moal, M. and Simon, H. (1993) Corticosterone in the range of stress-induced levels possesses reinforcing properties: implications for sensation-seeking behaviors. Proceedings of the National Academy of Sciences of the United States of America 90, 11738-11742.

Princz, Z., Orova, Z., Nagy, I., Jordan, D., Stuhec, I., Luzi, F., Verga, M. and Szendrö, Zs. (2007) Application of gnawing sticks in rabbit housing. World Rabbit Science 15, 29-36.

Princz, Z., Zotte, A.D., Metzger, Sz., Radnai, I., BiróNémeth, E., Orova, Z. and Szendrö, Zs. (2009) Response of fattening rabbits reared under different housing conditions: live performance and health status. Livestock Science 121, 86-91.

Puppe, B., Ernst, K., Schön, P. and Manteuffel, G.. (2007) Cognitive enrichment affects behavioural reactivity in domestic pigs. Applied Animal Behaviour Science 105, 75-86.

Rodarte, L.F., Docing, A., Galindo, F., Romano, M.C. and Valdez, R.A. (2004) The effect of environmental manipulation on behaviour, salivary cortisol, and growth of piglets weaned at 14 days of age. Journal of Applied Animal Welfare Science 7, 171-179.

Rolls, E.T. (1999) The Brain and Emotion. Oxford University Press, New York.

Rolls, E.T. (2007) Emotion Explained. Oxford University Press, Oxford, UK.

Salmon, G.K., Leslie, G., Roe, F.J.C. and Lee, P.N. (1990) Influence of food intake and sexual segregation on longevity organ weights and the incidence of nonneoplastic and neoplastic diseases in rats. Food and Chemical Toxicology 28, 39-48.

Schapiro, S.J., Nehete, P.N., Perlman, J.E., and Sastry, K.J. (2000) A comparison of cell-mediated immune responses in rhesus macaques houses singly, in groups or in pairs. Applied Animal Behaviour Science 68, 67-84.

Shaw, D.C. and Gallagher, R.H. (1984) Group or singly housed rats? In: Standards in Laboratory Animal Management, Proceedings of a LASA/UFAW Symposium. The Universities Federation for Animal Welfare, Potters Bar, UK, pp. 65-70.

Shepherdson, D.J., Carlstead, K.C. and Wielebnowski, N. (2004) Cross-institutional assessment of stress responses in zoo animals using longitudinal monitoring of faecal corticoids and behaviour. Animal Welfare 13, 105-113.

Sherwin, C.M., Haug, E., Terkelsen, N. and Vadgama, M. (2004) Studies on the motivation for burrowing by laboratory mice. Applied Animal Behaviour Science 88, 343-358. 
Shyne, A. (2006) Meta-analytic review of the effects of enrichment on stereotypic behavior in zoo mammals. Zoo Biology 25, 317-337.

Skalicky, M., Narath, E. and Viidik, A. (2001) Housing conditions influence the survival and body composition of ageing rats. Experimental Gerontology 36, 159-170.

Sorensen, D.B., Stub, C., Jegstrup, I.M., RitskesHoitinga, M. and Hansen, A.K. (2005) Fluctuating asymmetry in relation to stress and social status in inbred male Lewis rats. Scandinavian Journal of Laboratory Animal Science 32, 117-123.

Stevenson, M.F. (1983) The captive environment: its effect on exploratory and related behavioural responses in wild animals. In: Archer, J. and Birke, L.I.A. (eds) Exploration in Animals and Humans. Van Nostrand Reinhold, London, pp. 198-208.

Stevenson-Hinde, J. and Roper, R. (1975) Individual differences in reinforcing effects of song. Animal Behaviour 23, 729-734.

Struelens, E., Tuyttens, F.A.M., Janssen, A., Leroy, T., Audoorn, L., Vranken, E., de Baere, K., Odberg, F., Berckmans, D., Zoons, J. and Sonck, B. (2005) Design of laying nests in furnished cages: influence of nesting material, nest box position and seclusion. British Poultry Science 46, 9-15.

Struelens, E., Van Nuffel, A., Tuyttens, F.A.M., Audoorn, L., Vraken, E., Zoons, J., Berckmans, D., Ödberg, F., Van Dongen, S. and Sonck, B. (2008) Influence of nest seclusion and nesting material on pre-laying behaviour of laying hens. Applied Animal Behaviour Science 112, 106-119.

Swaisgood, R. and Shepherdson, D. (2006) Environmental enrichment as a strategy for mitigating stereotypies in zoo animals: a literature review and meta-analysis. In: Mason, G. and Rushen, J. (eds) Stereotypic Behaviour in Captive Animals: Fundamentals and Applications to Welfare. CAB International, Wallingford, United Kingdom pp. 256-285.

Taira, K. and Rolls, E.T. (1996) Receiving grooming as a reinforcer for the monkey. Physiology and Behaviour 59, 1189-1192.

Tarou, L.R., Bloomsmith, M.A. and Maple, T.L. (2005) Survey of stereotypic behavior in prosimians. American Journal of Primatology 65, 181-196.

Taylor, S.A. and Dewsbury, D.A. (1989) Male preferences for females of different reproductive conditions: a critical review. In: Macdonald, D.W., Mullerschwarze, D. and Natynczuk, S.E. (eds) Proceedings of the Conference on Chemical Signals in Vertebrates.

[AU 12] $\begin{gathered}\text { Oxford University Press, Oxford, UK, pp. 184-198. } \\ \text { Thodberg, K., Jensen, H.K., Herskin, M.S. and Jorgensen, E. }\end{gathered}$ (1999) Influence of environmental stimuli on nest building and farrowing behaviour in domestic sows. Applied Animal Behaviour Science 63, 131-144.

Uvnäs-Moberg, K., Widström, A.M., Marchini, G. and Winberg, J. (1987) Release of GI hormones in mother and infant by sensory stimulation. Acta Paediatrica Scandinavica 76, 851-860.

Van Hemel, P.E. (1972) Aggression as a reinforcer: operant behaviour in the mouse-killing rat. Journal of the Experimental Analysis of Behavior 17, 237-245.

Veissier, I., de Passillé, A.M.B., Després, G., Rushen J., Charpentier, I., Ramirez de la Fe, A.R. and Pradel, P. (2002) Does nutritive and non-nutritive sucking reduce other oral behaviours and stimulate rest in calves? Journal of Animal Science 80, 2574-2587.

Visser, E.K., Ellis, A.D. and Van Reenen, C.G. (2008) The effect of two different housing conditions on the welfare of young horses stables for the first time. Applied Animal Behaviour Science 114, 521-533.

Wahidin, A. (2006) Time and the Prison Experience. Available at: www.socresonline.org.uk/11/1/wahidin. html (accessed 11 October 2009).

Waiblinger, E. and Konig, B. (2004) Refinement of gerbil housing and husbandry in the laboratory. Alternatives to Laboratory Animals 32, 163-169.

Walker, A.W. and Hughes, B.O. (1998) Egg shell colour is affected by laying cage design. British Poultry Science 39, 696-699.

Walker, K. (1990) Desire and ability: hormones and the regulation of female sexual behaviour. Neuroscience and Biobehavioural Reviews 14, 233-241.

Watson, S.L., Shively, C.A., Kaplan, J.R. and Line, S.W. (1998) Effects of chronic social separation on cardiovascular disease in female cynomogus monkeys. Atherosclerosis 137, 259-266.

Weeks, C.A. and Nicol, C.J. (2006) Behavioural needs, priorities and preferences of laying hens. World's Poultry Science Journal 62, 296-307.

Weiss, J.M. (1970) Somatic effects of predictable and unpredictable shock. Psychosomatic Medicine 32, 397-408.

Weiss, J.M. (1971) Effects of coping behavior in different warning signal conditions on stress pathology in rats. Journal of Comparative and Physiological Psychology 77, 1-13.

Wells, D.L. (2009) Sensory stimulation as environmental enrichment for captive animals: a review. Applied Animal Behaviour Science 118, 1-11.

Widowski, T.M. and Curtis, S.E. (1990) The influence of straw, cloth tassel, or both on the prepartum behavior of sows. Applied Animal Behaviour Science 27, 53-71.

Widowski, T.M., Cottrell, T., Dewey, C.E. and Friendship, R.M. (2003) Observations of piglet-directed behaviour patterns and skin lesions in eleven commercial swine herds. Journal of Swine Health and Production 11, 181-185.

Widowski, T.M., Yuan, Y. and Gardner, J.M. (2005) Effect of accommodating sucking and nosing on the behavior of artificially reared piglets. Laboratory Animals $39,240-250$.
[AU 12]

[AU 12]

[AU 12] 
Wiedenmayer, C. (1996) Effect of cage size on the ontogeny of stereotyped behaviour in gerbils. Applied Animal Behaviour Science 47, 225-233.

Wiedenmayer, C. (1997) Causation of the ontogenetic development of stereotypic digging in gerbils. Animal Behaviour 53, 461-470.

Wiedenmayer, C. (1997) Stereotypies resulting from a deviation in the ontogenetic development of gerbils.

[AU 12] Behavioural Processes 39, 215-221.

Wiepkema, P.R. (1971) Positive feedbacks at work during feeding. Behaviour 39, 266-273.

Wischner, D., Kemper, N. and Krieter, J. (2009) Nestbuilding behaviour in sows and consequences for pig husbandry. Livestock Science 124, 1-8.

Wood-Gush, D.G., Stolba, A. and Miller, C. (1983) Exploration in farm animals and animal husbandry. In: Archer, J. and Birke, L.I.A. (eds.) Exploration in
Animals and Humans. Van Nostrand Reinhold, London, pp. 198-208.

Yue, S. and Duncan, I.J.H. (2003) Frustrated nesting behaviour: relation to extra-cuticular shell calcium and bone strength in White Leghorn hens. British Poultry Science 39, 696-699.

Zhang, G., Swaisgood, R.R. and Zhang, H. (2004) Evaluation of behavioral factors influencing reproductive success and failure in captive giant pandas. Zoo Biology 23, 15-31.

Zimmerman, P.H., Koene, P. and Van Hooff, J.A.R.A.M. (2000) Thwarting of behaviour in different contexts and the gakel-call in the laying hen. Applied Animal Behaviour Science 69, 255-264.

Zuckerman, M. (1994) Behavioral Expressions and Biosocial Bases of Sensation Seeking. Cambridge University Press, Cambridge, UK.

Author Query:

[AU 1]: Ref needed

[AU 2]: This might be Duncan and Wood Gush (1972) - otherwise ref needed

[AU 3]: Date and other details needed

[AU 4]: All refs need adding to the refs list

[AU 5]: Ref needed - or could this be McFarland, 1987

[AU 6]: Is it right that the scales on the y-axes in the 2 graphs in Fig. 7.5 are different?

[AU 7]: This might be de Passile and Rushen, 2006, otherwise ref needed

[AU 8]: Both refs needed

[AU 9]: There are 2 Widenmayer 1997 refs - is the first one 1997a

[AU 10]: There are 2 Widenmayer 1997 refs - is the second one $1997 \mathrm{~b}$

[AU 11]: Proposed edition

[AU 12]: Not cited in text - where should it be cited or should it be deleted?

[AU 13]: Not cited in text - where should it be cited or should it be deleted? Could it be the missing Rushen and de Passillé ref on ms p. 9, line 2?

[AU 14]: Not cited in text - where should it be cited or should it be deleted? Could it be the McFarland 1980 ref cited in Fig. 7.4 caption? 